\title{
Article \\ Effect of Grain Size and Micromorphology of Cu Foil on the Velocity of Flyer of Exploding Foil Detonator
}

\author{
Kehua Han ${ }^{1,2}$, Peng Deng ${ }^{1}$, Enyi Chu ${ }^{2}$ and Qingjie Jiao ${ }^{1, *}$ \\ 1 State Key Laboratory of Explosion Science and Technology, Beijing Institute of Technology, \\ Beijing 100081, China; 3120195169@bit.edu.cn (K.H.); 3120195115@bit.edu.cn (P.D.) \\ 2 National Key Laboratory of Applied Physics and Chemistry, Shaanxi Applied Physics \\ and Chemistry Research Institute, Xi'an 710061, China; nickhkh@163.com \\ * Correspondence: jqj@bit.edu.cn
}

Citation: Han, K.; Deng, P.; Chu, E.; Jiao, Q. Effect of Grain Size and Micromorphology of $\mathrm{Cu}$ Foil on the Velocity of Flyer of Exploding Foil Detonator. Appl. Sci. 2021, 11, 6598. https://doi.org/10.3390/app11146598

Academic Editor: Alfio Dario Grasso

Received: 19 June 2021

Accepted: 1 July 2021

Published: 18 July 2021

Publisher's Note: MDPI stays neutral with regard to jurisdictional claims in published maps and institutional affiliations.

Copyright: (c) 2021 by the authors. Licensee MDPI, Basel, Switzerland. This article is an open access article distributed under the terms and conditions of the Creative Commons Attribution (CC BY) license (https:// creativecommons.org/licenses/by/ $4.0 /)$.

\begin{abstract}
In this paper, the effect of grain size and micromorphology of $\mathrm{Cu}$ foil on the velocity of the flyer of an exploding foil detonator was studied. A Cu foil with different grain sizes and micromorphologies was prepared by the physical vapor deposition sputtering method. The flyer velocity of the $\mathrm{Cu}$ foil was measured by the photon Doppler technique (PDT). The influence of the grain size and micromorphology of the $\mathrm{Cu}$ foil (which was the core transducer of the exploding foil detonator) on the flyer velocity and reacted morphology was discussed. The results show that the grain size and micromorphology of the $\mathrm{Cu}$ film can greatly affect the velocity and morphology of the flyer. The grain size of the $\mathrm{Cu}$ film is more uniform, and the stimulus response in the middle area of the bridge foil is more concentrated. In addition, the current density becomes more uniform, resulting in a better explosion performance. Consequently, the speed of the formed flyer becomes higher, leading to a smoother flyer surface, which is more conductive to energy conversion.
\end{abstract}

Keywords: exploding foil detonator; copper foil; grain size; flyer morphology; flyer velocity

\section{Introduction}

The shape and material nature of $\mathrm{Cu}$ foil, which affects the energy deposition, plasma output ability and flyer velocity, is the most researched topic on exploding foil detonators [1-3], which are considered as the key materials for electronic safe and arm systems for rocket motor ignition, fuzing, ammunition, and flight termination applications [4-12]. The velocity and shape of the flyer are two key factors that affect the energy-output effect of exploding foil initiators. They are the most important characterization indexes for exploding foil initiators and have shown some important referenced values for the design of the reliability, evaluation, and performance optimization of exploding foil initiators [13,14]. At present, the theoretical and experimental researches on the flyer velocity of exploding foil initiators is relatively mature, and a variety of velocity testing techniques of small flyers have been mastered. Moreover, the various parameters of the exploding foil initiator on the flyer velocity have also been investigated from a macro point of view [15-17]. The macroscopic properties of materials depend not only on their chemical composition, but also, to a greater extent, on their micromorphology and grain size [18,19].

Usually, the film grown by various atomic deposition techniques is generally polycrystalline with a strong texture. The texture characteristics have a great influence on the magnetic properties, electrical properties, and microstructure density of the film, which often directly affects the physical properties, surface, and interface structures of the devices $[20,21]$. As a new kind of metal film, $\mathrm{Cu}$ foil is considered as a potential core energy converter of next-generation exploding foil detonators. Although, $\mathrm{Cu}$ foils have attracted much attention in the fields of fuse, initiators, and pyrotechnics, unfortunately, the influence of the micromorphology and grain size of $\mathrm{Cu}$ foils on the velocity and morphology 
of the flyer has not been reported [22-25]. However, systematically studying the effect of different characteristics of the $\mathrm{Cu}$ foil on the velocity of the flyer is of great significance.

In this paper, the flyer velocity of $\mathrm{Cu}$ foils with different micromorphologies and grain sizes was studied during an electric explosion. The $\mathrm{Cu}$ foils with different parameters were prepared by the physical vapor deposition sputtering method. In addition, the morphology of the flyer was observed and collected. The influence of the micromorphology and grain size of the $\mathrm{Cu}$ foil on the flyer velocity and flyer morphology was investigated. This study will provide the technical support and theoretical basis for the preparation of $\mathrm{Cu}$ foil and for the reliability of exploding foil detonators.

\section{Experimental Section}

\subsection{Preparation of Samples}

According to the experiments in previous literature [22,23], pure $\mathrm{Cu}$ was used as the target material. Polyimide film with a thickness of $25 \mu \mathrm{m}$ was used as the substrate, which was sputtered by a physical vapor deposition (PVD) coating machine of KS40 unbalanced magnetron sputtering apparatus, according to the preparation method detailed in the literature [26]. Under different sputtering power conditions, a copper foil with a thickness of $4.0 \mu \mathrm{m}$ is prepared, and the deviation is less than $3 \%$. The main sputtering process is as follows: surface pretreatment of polyimide film $\rightarrow$ placing in coating equipment $\rightarrow$ vacuumizing $\rightarrow$ surface treatment in vacuum cavity $\rightarrow$ sputtering $\mathrm{Cu}$ (purity greater than $99.99 \%$, thickness of 50,000 a 70,000 a) $\rightarrow$ internal stress relief treatment $\rightarrow$ taking out samples $\rightarrow$ surface cleaning and treatment $\rightarrow$ test and analysis of the technical parameters.

\subsection{Characterizations}

The surface morphology of the samples was characterized by a VEGA TS5136XM scanning electron microscope produced by TESCAN company of Czech Republic, with a magnification of 800,000 times and a resolution of $30 \mathrm{KV}(1.2 \mathrm{~nm}), 3 \mathrm{KV}(3.0 \mathrm{~nm})$. The three-dimensional size of the bridge area of the metal bridge foil was measured by a Dektak 150 step-meter produced by Veeco company of the USA. Additionally, the threedimensional image, surface roughness, and internal stress of the film were obtained.

\subsection{The Test System of Flyer Speed Measurement}

The flyer velocity measuring test system is mainly composed of the flyer generating test device and flyer speed measuring test device. The principle of the test system is shown in Figure 1.

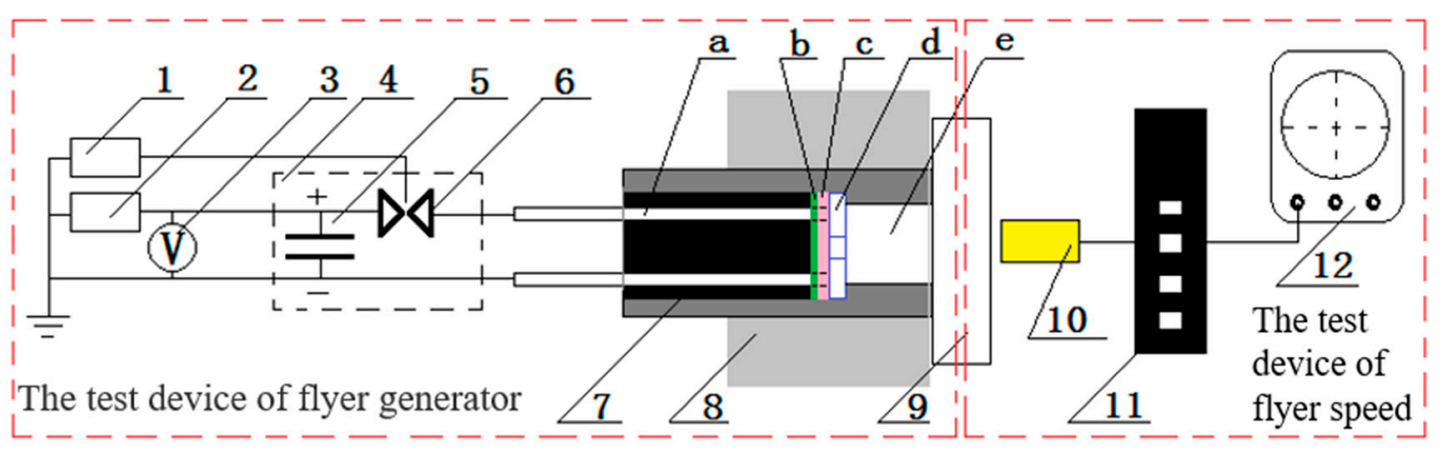

1 - Trigger power supply; 2 - High voltage power supply; 3 - Digital high voltage meter; 4 - Pulse power source; 5 - High voltage pulse capacitor; 6 - Cold cathode trigger tube (high voltage switch); 7 - Test sample; 8 - Fixed fixture; 9 - Slide glass; 10 - Optical fiber probe; 11 - Photon Doppler velocimeter; 12 - Digital oscilloscope a-Electrode plug; b-Cu foil; c-Polyimide flyer; d-Accelerating chamber; e-Cavity

Figure 1. Schematic diagram of the flyer velocity measuring test system. 
The high-voltage pulse capacitor in the high-voltage pulse power source is closed instantaneously through the high-voltage switch, releasing a narrow pulse and large current, which excites the metal bridge foil into having an electrical explosion, and which cuts and drives the polyimide flyer to move at a high speed. The optical signal reflected by the flyer is collected by the optical fiber probe, and the photoelectric conversion is realized. The electrical signal is amplified and then recorded by the oscilloscope. The original signal collected by the oscilloscope can be fast-Fourier-transformed to obtain the velocity history of the flyer.

\subsubsection{The Test Device of Flyer Generation}

The experiment equipment mainly includes high voltage power supplied with an output voltage of $0 \sim 4 \mathrm{kV}$ and accuracy of $1 \%$; pulse trigger power supplied with an output voltage of $0 \sim 3 \mathrm{kV}$, a pulse rise time of no more than $100 \mathrm{~ns}$, and a pulse fall time of no more than $1 \mu \mathrm{s}$; a digital high voltage meter with an input impedance of $1000 \mathrm{M} \Omega$ and measurement accuracy of $1 \%$; and a high voltage pulse power source. Among them, the high voltage pulse power source is mainly composed of a high voltage pulse capacitor of CT41L/0.2 $\mu \mathrm{F} / 3.0 \mathrm{kV}$ and a cold cathode trigger tube (high voltage switch) of RQ-8001.

\subsubsection{Velocity Measuring Test Device of Flyer}

According to the literature $[15,16]$, the velocity measurement of the flyer is carried out by using PDT. In the PDT speed measurement system, the fiber with a core diameter of $105 \mu \mathrm{m}$ is used to output a laser and receive a reflected optical signal. A frequency difference signal is recorded by a $33 \mathrm{GHz}$ high-bandwidth oscilloscope, and the velocity curve of the flyer is obtained by MATLAB analysis. The single frequency laser emitted by the laser is divided into two beams by the beam splitter, one of which is the reference light while the other is vertically irradiated on the surface of the flyer, and the reflected light (called signal light) on the surface of the flyer is collected by the optical probe. The signal light and the reference light are combined and produce the interference fringes, which are received and recorded with the photodetector.

\section{Results and Discussion}

\subsection{SEM Analysis of Cu Foil}

The SEM photographs of copper film samples with three kinds of sputtering power and a magnification of 1000 times are shown in Figure 2, in which Figure 2a-c corresponds to Sample A, Sample B, and Sample C, respectively. Furthermore, the corresponding DC power of Sample C is $100 \mathrm{~W}, 400 \mathrm{~W}$, and $800 \mathrm{~W}$.
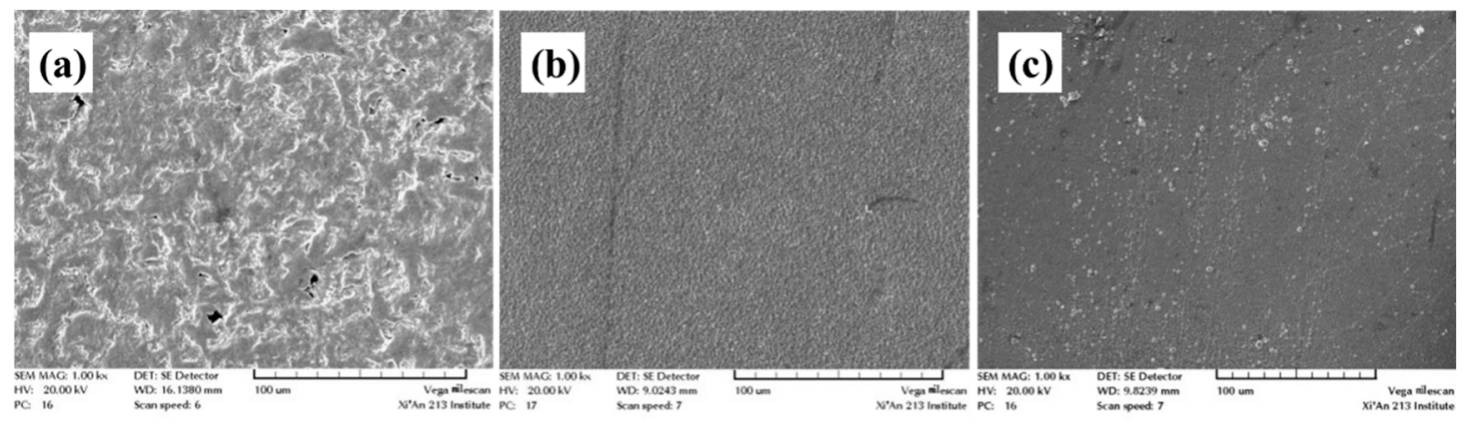

Figure 2. SEM images of Cu foil. (a) Sample A, (b) Sample B, and (c) Sample C.

In Figure 2, it can be seen that the quality of the copper film is determined by the sputtering power, meaning that the higher the sputtering power, the better the compactness of the copper film. Moreover, the smaller the grain size becomes, the more uniform the grain distribution becomes. With the increase of the sputtering power, the compactness of 
the film is significantly improved. The corresponding photographs of samples are shown in Figures 4 and 5, which are magnified at 10,000 times and 20,000 times, respectively.

In Figures 3 and 4 , the influence of the sputtering power on the quality of the copper film can be clearly observed. There are many pores and cracks on the copper film of Sample A, obtained at a sputtering power of $100 \mathrm{~W}$. The density of the copper film of Sample B obtained at a sputtering power of $400 \mathrm{~W}$ is better than that of Sample C obtained with a sputtering power of $100 \mathrm{~W}$; nevertheless, the distribution of the grain size is not uniform. Compared with Samples A and B, the density and grain size uniformity of Sample C, which is obtained at a sputtering power of $800 \mathrm{~W}$, are greatly improved. Figure 5 shows the SEM images of the microstructure in the copper film.

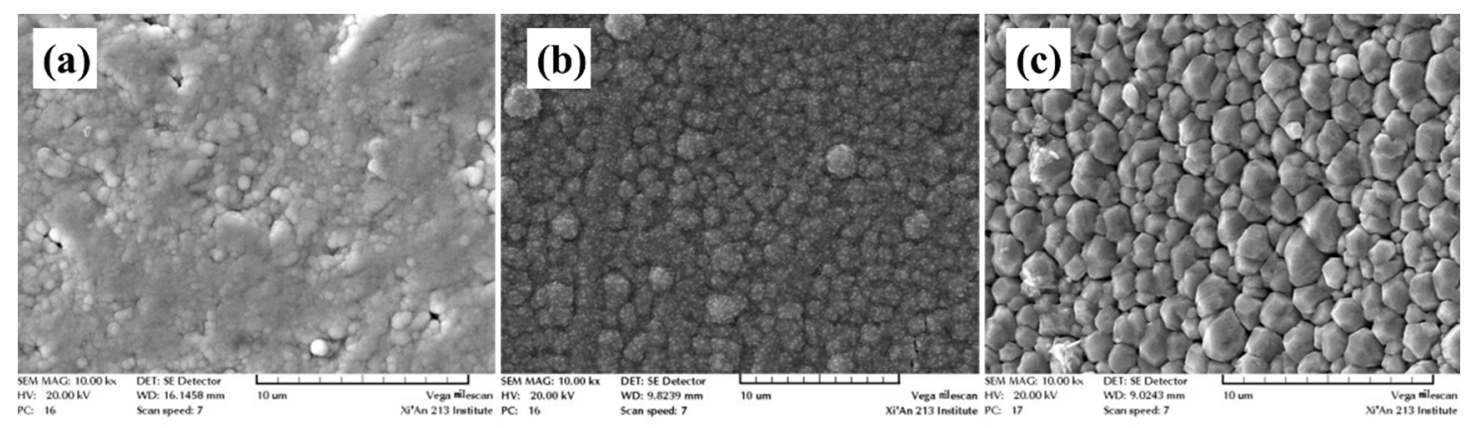

Figure 3. SEM images of Cu foil. (a) Sample A, (b) Sample B, (c) Sample C.
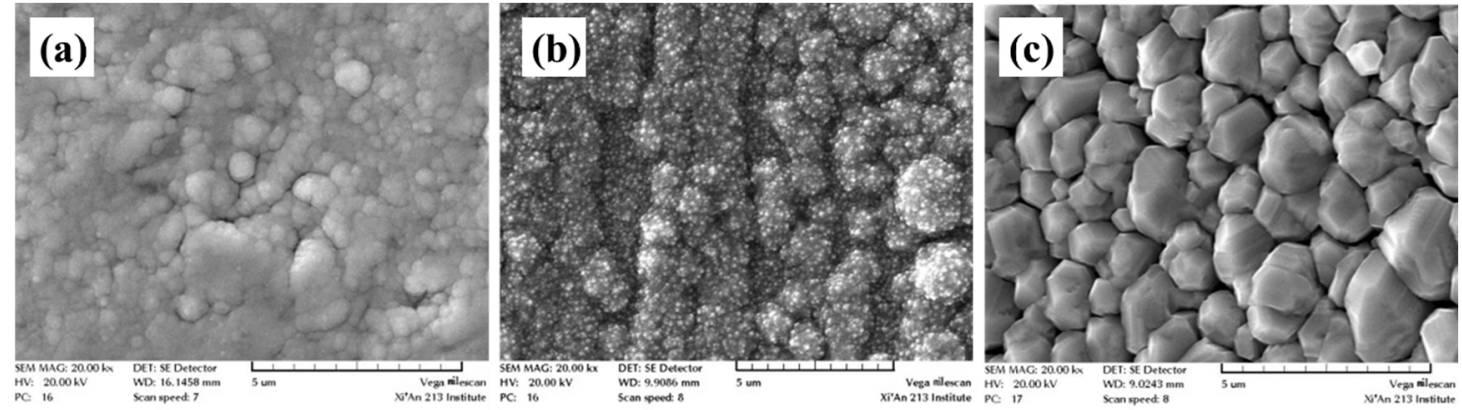

Figure 4. SEM images of Cu foil. (a) Sample A, (b) Sample B, and (c) Sample C.
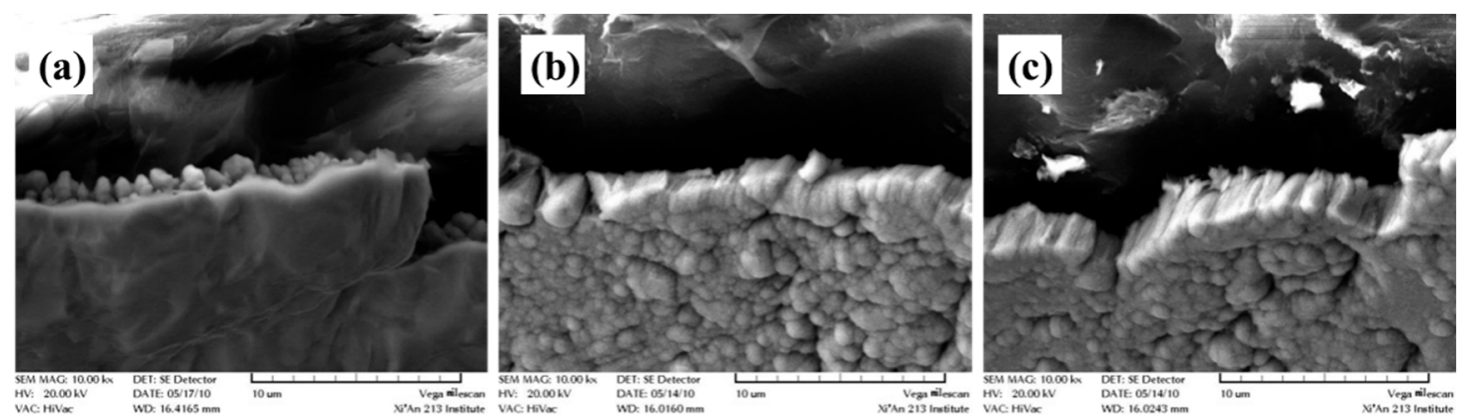

Figure 5. SEM images of copper film. (a) Sample A, (b) Sample B, and (c) Sample C.

Because of the accumulation during the crystal growth of metal $\mathrm{Cu}$, a variety of depressions are generated in the middle of the crystal. From the microstructure of the $\mathrm{Cu}$ foil in Figure 5, it could be observed that this phenomenon of Sample A occurred because of the partial polymerization between particles during the column growth of the metal film, and furthermore the particle size was uneven. The distribution of the magnetron sputtering 
particles of Samples B and C is relatively uniform, and the growth is columnar and vertical to the surface. As shown in Figures 2-5, when the sputtering power reaches $800 \mathrm{~W}$, the grain size of the film decreases further and the film becomes denser, but at this time there are many larger particles in the field of view. The reason for this phenomenon may be that at a $800-\mathrm{W}$ sputtering power, the deposition rate of copper has reached a great value under this condition. Such a rapid deposition rate destroys the rearrangement process of copper atoms deposited on the substrate, which makes the copper atoms deposited on the base material hardly diffused and rearranged, leading to an excessive accumulation appearing with copper atoms in some positions, which corresponds to the larger copper grains that appear in the SEM images.

\subsection{The Test Results}

The bridge areas with the same size of $0.5 \mathrm{~mm}(\mathrm{~L}) \times 0.5 \mathrm{~mm}(\mathrm{~W}) \times 4 \mu \mathrm{m}(\mathrm{d})$ were obtained by etching the three $\mathrm{Cu}$ foils above. The physical photographs are shown in Figure 6.

(a)

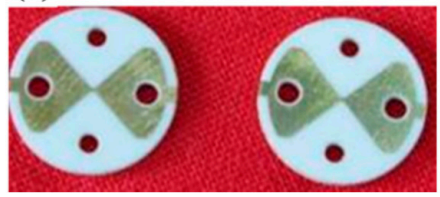

(b)

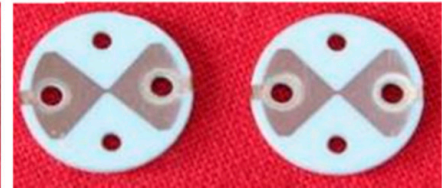

(c)

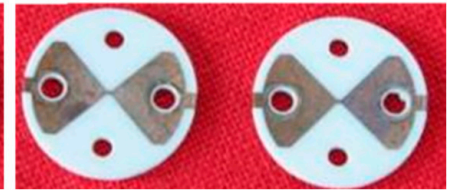

Figure 6. The photographs of (a) Sample A, (b) Sample B, and (c) Sample C with a 5-mm diameter.

Using the test system in Figure 1, the flyer speed of the three samples in Figure 6 is tested under the condition of different driving voltages. The same discharge device was used in the test. The discharge capacitance was $0.2 \mu \mathrm{F}$ and the driving voltage was $1.1 \mathrm{kV}, 1.3 \mathrm{kV}, 1.5 \mathrm{kV}, 1.8 \mathrm{kV}$, and $2.0 \mathrm{kV}$, respectively. When the loading voltage is $2.0 \mathrm{kV}$, the original frequency spectrum waveform of the collected flyer speed is shown in Figure 7a. The flyer speed history obtained in the test is shown in Figure 7b-d. The effective measured time is about $2 \mu \mathrm{s}$.
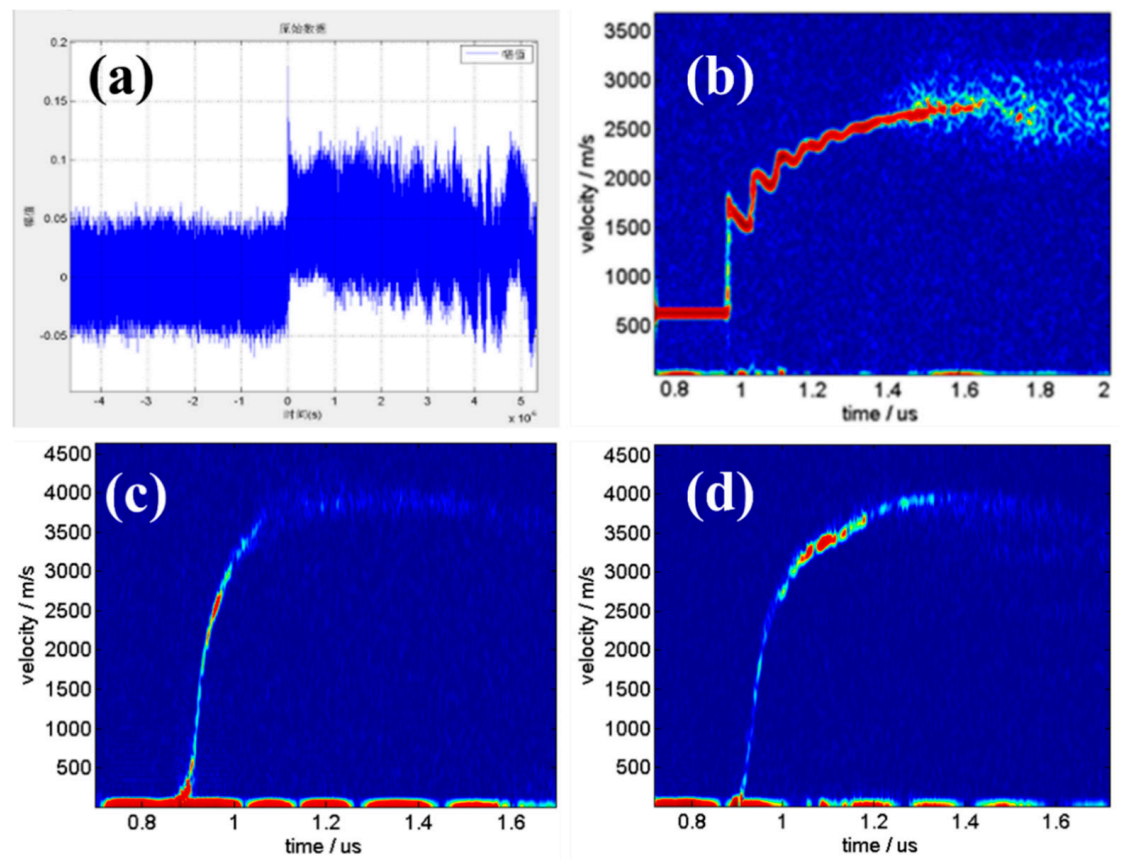

Figure 7. (a) The spectrum diagram of the flyer velocity, and the Fourier transform velocity spectrum $(2.0 \mathrm{kV})$ of (b) Sample A, (c) Sample B, and (d) Sample C. 
In Figure 7, it can be observed that for all three samples, the inflection point of the flyer speed appears at about $0.92 \mu$ s. Before that, the flyer speed rises rapidly, reaching $75 \%$ of the final speed within about $100 \mathrm{~ns}$. After the inflection point, the speed of the flyer increases relatively slowly. The remaining speed of $25 \%$ increases within about $100 \mathrm{~ns}$. The speed history curves of the three samples under the driving voltages of $1.5 \mathrm{kV}$ and $2.0 \mathrm{kV}$ are shown in Figure 8.
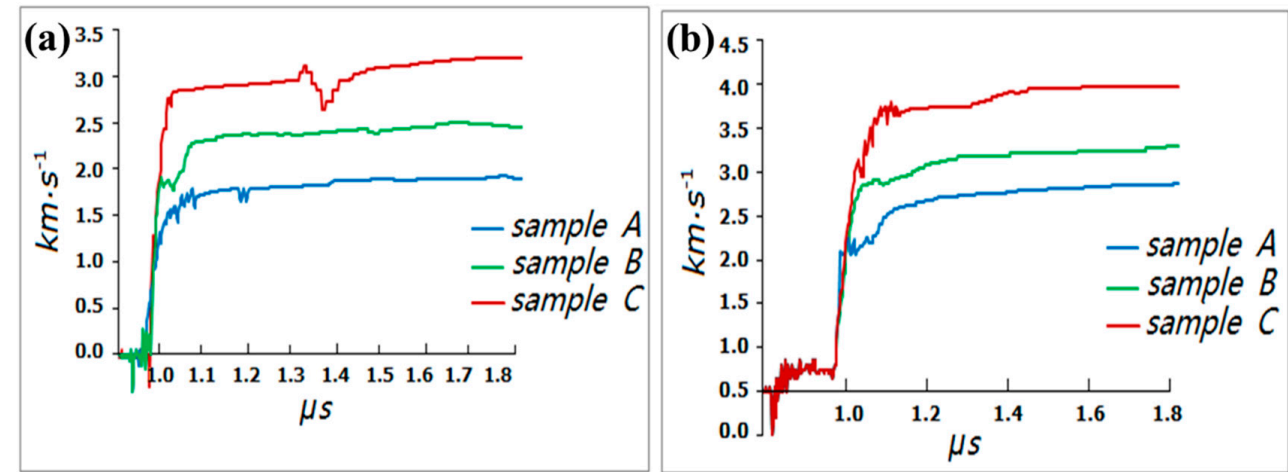

Figure 8. The displacement curves of the flyer velocity for three samples: (a) $1.5 \mathrm{kV}$ and (b) $2.0 \mathrm{kV}$.

It can be seen from Figure 8 that the flyer speed of Sample A is the smallest under the same driving voltage, followed by that of Samples B and C. It can be obtained from the experimental data that, under the same driving voltage, the compactness and the uniformity of the grain size of the $\mathrm{Cu}$ film have a greater influence on the flyer speed. The compactness and grain size of the $\mathrm{Cu}$ film are more uniform, and the flyer speed is higher, which is more beneficial for energy conversion.

According to the calculation formula of metal resistivity:

$$
\rho=R \frac{\mathrm{t}}{F}
$$

$\rho:$ Resistivity/m $\Omega . m m ;$

$R:$ Resistance $/ \mathrm{m} \Omega$;

t: Film thickness;

$F$ : The dimensionless geometric factor, which is related to the thickness, area, position, and interlayer material of the samples.

From Formula (1), it can be seen that the relation between the resistivity and resistance of a $\mathrm{Cu}$ foil with the same thickness is $\rho \propto \mathrm{R}$.

The resistivity of metals is determined by their purity, density, and grain size. Copper foil has a polycrystalline structure. In addition, the larger the grain size becomes, the more the range of grain boundaries and the resistivity will be reduced. For the copper foil, the number of grain boundaries will greatly affect the resistivity of copper. The grain size of $\mathrm{Cu}$ foil is closely related to the sputtering power, and the sputtering rate is directly proportional to the sputtering power. The expression of the sputtering rate is shown in Equation (2).

$$
S=\frac{3 a}{4 \pi^{2}} \frac{4 m_{i} m_{t}}{m_{i}+m_{t}} \frac{E}{U_{0}}
$$

$E$ : Incident ion energy;

$m_{i}$ : Mass of incident ion;

$m_{t}$ : Changed ionic mass;

$U_{0}$ : Surface building energy of target;

$a: a=0.7 \sim 1.4$.

With the change of sputtering conditions, metal particles will show different effects of surface diffusion, bulk diffusion, and atom shielding, thus forming different microstruc- 
tures. From the different sputtering conditions controlled by the equipment, the diffusion of $\mathrm{Cu}$ particles will be affected, and a concave morphology will be formed on the surface of the copper film. At the same time, if the construction conditions are not suitable, the transverse diffusion of $\mathrm{Cu}$ atoms will occur too late to diffuse laterally and produce a large number of longitudinal stackings.

When the sputtering power is small, the grain shape of the $\mathrm{Cu}$ foil is irregular and the grain size is small. The number of grain boundaries increases greatly and the grain boundary resistance increases. With the continuous improvement of the sputtering power and rate, the grain size of the sputtered $\mathrm{Cu}$ foil becomes larger, the range of grain boundaries becomes smaller, and the resistivity becomes smaller, which is more conductive to energy conversion and to obtaining enough sublimation heat or melting heat. Driven by the narrow pulse high energy, the electric explosion produces more plasma, the ability for cutting and pasting the flyer becomes stronger, and the speed of the flyer becomes higher. Under the same driving voltage, the density and the uniformity of the grain size of the $\mathrm{Cu}$ film have a great influence on the velocity of the flyer. The higher density of the $\mathrm{Cu}$ film and greater uniformity of the grain size will result in a higher velocity of the flyer, which is more beneficial to energy conversion. Figure 9 shows the flyer velocity test results of $\mathrm{Cu}$ foils with different grain sizes, after an electric explosion and under different driving voltages.

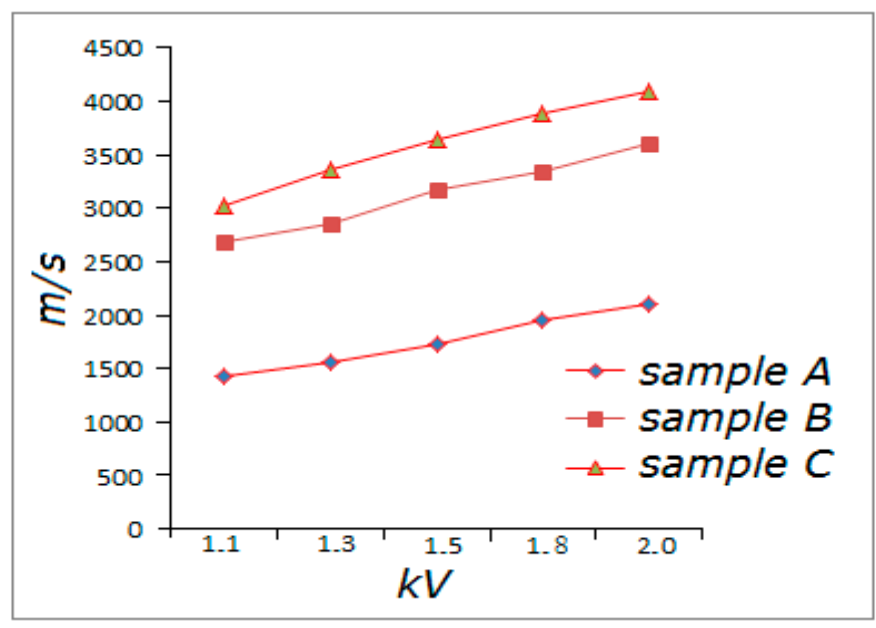

Figure 9. The flyer speed of three samples under different driving voltages.

It can be seen from Figure 9 that in the $\mathrm{Cu}$ foil samples with the same grain size, the flyer speed is proportional to the driving voltage, namely, with an increase in the driving voltage, the flyer speed will rise. When the bridge foil explodes, the resistance increases sharply due to the vaporization of the materials. Thus, the voltage reaches the peak value, and then the vaporized material ionizes and produces plasma under the induced voltage. Since the conductivity of plasma leads to a sharp drop in voltage, with the increase of the driving voltage, more Joule heat is generated in the unit of time of exploding foil, resulting in the acceleration of the phase transformation rate, which improves the induction voltage, enhances the plasma output performance, and finally greatly improves the flyer speed.

\subsection{The Morphology Analysis}

After the electric explosion of the above three samples under a driving voltage of $2.0 \mathrm{kV}$, the photographs of the bridge area were taken and are shown in Figure 10. 
(a)

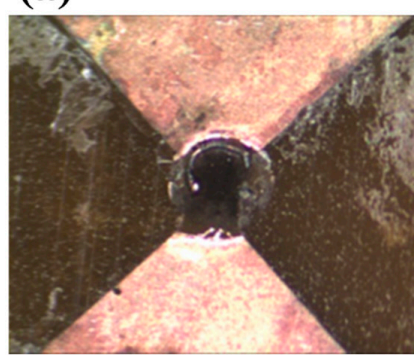

(b)

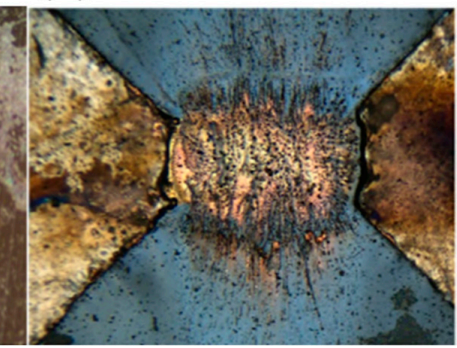

(c)

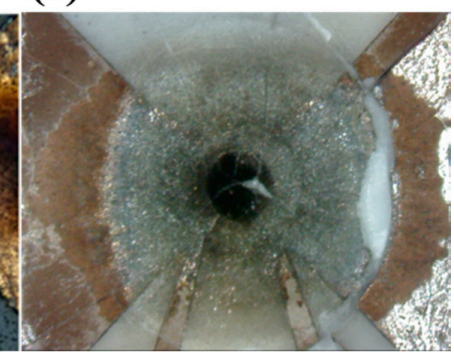

Figure 10. Images of the bridge foil electric explosion $(2.0 \mathrm{kV})$ : (a) Sample A, (b) Sample B, and (c) Sample C.

As shown in Figure 10, the electric explosion occurred locally in the center of the bridge area of Sample A, and there were traces of electric explosion in the center of the bridge area. However, a large number of metal bridge foils still existed. In the bridge area of Sample B, the electric explosion occurred completely, except that some metal copper slag existed. In the bridge area of Sample C, the electric explosion was relatively complete, with only a small amount of residue, and the explosion trace was obvious. During the electrical explosion of the metal bridge foil, due to the size of the bridge area being small and the loaded pulse current being $\mathrm{kA}$ level, the current density flowing through the bridge area is relatively concentrated. When the grains of the bridge foil are not uniform and there are many pores and cracks in the $\mathrm{Cu}$ microparticles, the reaction in the middle area of the bridge foil is not concentrated and the current density is not uniform, which leads to an incomplete electrical explosion.

After the electric explosion at a driving voltage of $2.0 \mathrm{kV}$, the flyers of the bridge foils for the three samples were collected. SEM was also used for morphology analysis. The morphology of the collected flyer was observed. The results are shown in Figure 11.

In Figure 11, it can be observed that for Sample A, the center of the flyer after the electric explosion has been broken and a perforation formed. For Sample B, the surface of the flyer after the electric explosion has a large curvature, and the shape of the flyer is like a bowl. Moreover, there is an irregular shape that appears in the center, which is critical to the broken shape. For Sample C, the flyer is relatively complete and the shape of the flyer is like a cap. The surface of the flyer is relatively flat. After the measurement, the diameter of the three kinds of flyers is consistent with that of the accelerating chamber.

According to the electric explosion process of the metal bridge foil, when the narrow pulse and large current output by a high voltage pulse power source pass through the $\mathrm{Cu}$ foil, the bridge area of the bridge foil generates a lot of heat due to the Joule effect and will instantly experience the phase transition process of solid-liquid-gas-plasma, resulting in an electric explosion and generating a lot of high-temperature and high-pressure plasma. Under the constraint of the accelerating chamber, the polyimide film is sheared to form the flyer. It can be seen from the above results that in the sputtering process of the $\mathrm{Cu}$ film, the quality of the metal film is determined by the sputtering power. When the sputtering power becomes higher, the metal grain size becomes smaller and the grain distribution is more uniform. A complete morphology of the $\mathrm{Cu}$ foil without voids will be obtained.

At the moment, when a current at a high-energy density passes through and is heated, the distribution of the premelting temperature in each part of the bridge region is relatively consistent. The compactness of the foil is poor, due to the phenomenon of delamination and voids in the micromorphology of the bridge foil. During the electric explosion, the problem of an inconsistent temperature distribution in the premelting heating process of the metal bridge zone is bound to occur, which will cause the possibility that a part of the metal crystal will form plasma while another part of the metal crystal will still be in the previous station. Thus, the electric explosion is incomplete, and the plasma produced is not uniform, leading to a decrease in the formation efficiency of plasma. Under the conditions of the stress concentration in the middle region and the constraint of the acceleration chamber, the 
pressure acting on the flyer is not uniform, and the flyer is unstable after being impacted by the plasma.
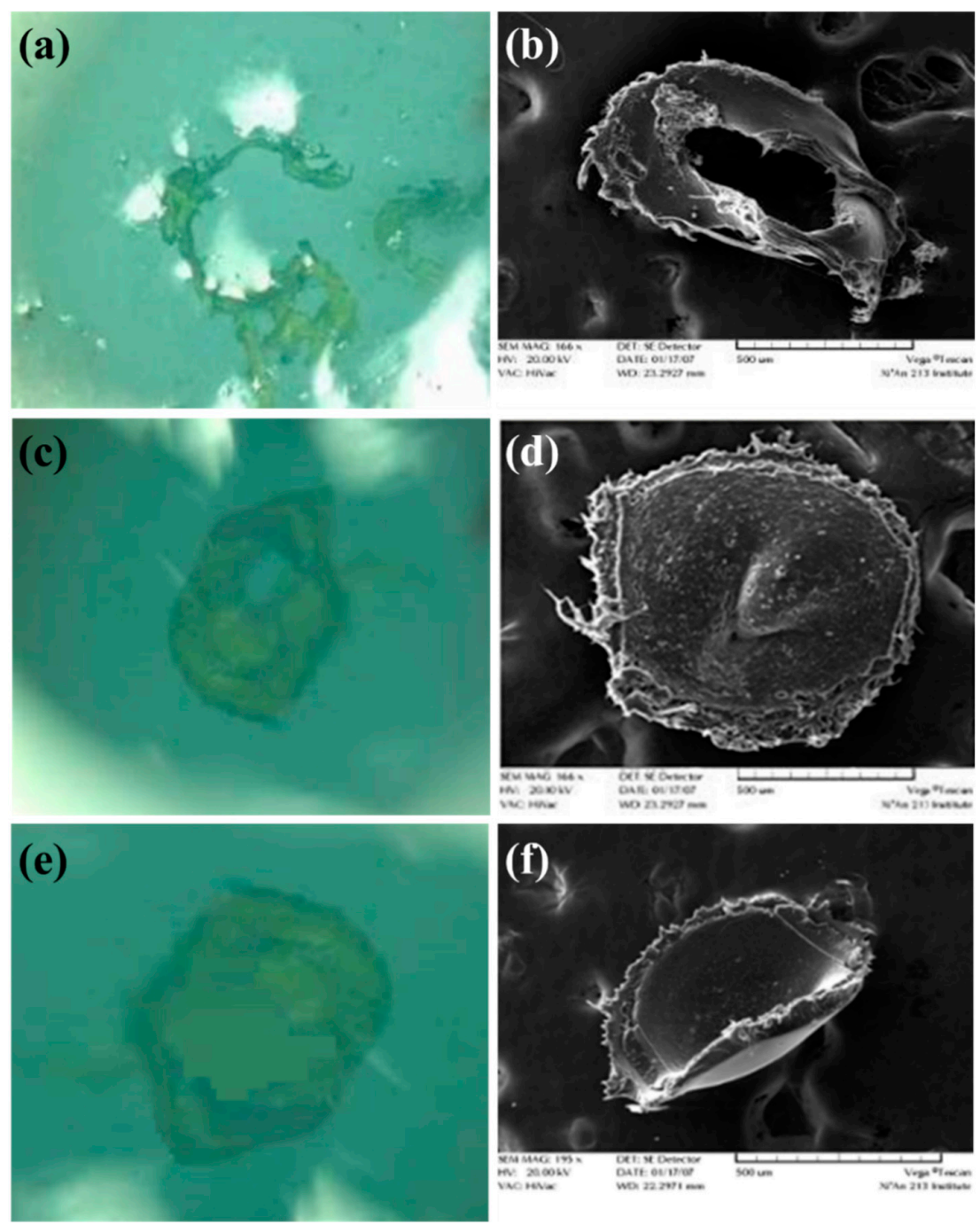

Figure 11. The morphology of flyers $(2.0 \mathrm{kV})$ : $(\mathbf{a}, \mathbf{b})$ Sample A, (c,d) Sample B, and (e,f) Sample C.

As a result, the flyer can easily be torn in the center of the energy concentration during the process of being sheared, and can be ruptured during the process of high-speed flight in the acceleration chamber. In the process of electrical explosion, the current converges to the center of the bridge foil, and thus the electrical explosion stability is fine. However, it is easy to produce a stress concentration in the center of the flyer, and the shape of the flyer is not planar under the constraint of the acceleration chamber.

\section{Conclusions}

In summary, the effect of the grain size and morphology of the $\mathrm{Cu}$ foil on the velocity of the flyer of an exploding foil detonator was investigated. A $\mathrm{Cu}$ foil with different grain sizes and micromorphologies was prepared by the physical vapor deposition sputtering method. Additionally, the flyer velocity of the $\mathrm{Cu}$ foil was measured during electric explosion by PDT. The results showed the influence of the grain size and micromorphology of the $\mathrm{Cu}$ foil on the flyer velocity. The grain size of the $\mathrm{Cu}$ film can greatly affect the velocity and morphology of the flyer. The grain size of the $\mathrm{Cu}$ film is more uniform, the compactness is better, and the stimulus response in the middle area of the bridge foil is more concentrated. In addition, the current density becomes more uniform, resulting in a 
better explosion performance, which is more conducive to energy conversion. This work offered a new and important understanding for the design and preparation of the $\mathrm{Cu}$ foil of exploding foil detonators.

Author Contributions: Conceptualization, Q.J. and E.C.; methodology, K.H.; software, K.H.; validation, formal analysis, investigation, resources, data curation, writing-original draft preparation, and visualization, K.H. and P.D.; writing—-review and editing, P.D.; supervision, Q.J.; project administration, E.C.; funding acquisition, Q.J. All authors have read and agreed to the published version of the manuscript.

Funding: This research received no external funding.

Institutional Review Board Statement: Not applicable.

Informed Consent Statement: Not applicable.

Data Availability Statement: Not applicable.

Conflicts of Interest: The authors declare no conflict of interest.

\section{References}

1. Yan, K.; Van Heesch, E.; Nair, S.; Pemen, A. A triggered spark-gap switch for high-repetition rate high-voltage pulse generation. J. Electrost. 2003, 57, 29-33. [CrossRef]

2. Yang, Z.; Wang, K.; Zhu, P.; Liu, P.; Zhang, Q.; Xu, C.; Jian, H.-T.; Shen, R.-Q. A reusable planar triggered spark-gap switch batched-fabricated with PCB technology for medium- and low-voltage pulse power systems. Def. Technol. 2020, 2020. [CrossRef]

3. Wang, Y.; Dai, J.; Xu, J.; Shen, Y.; Wang, C.-A.; Ye, Y.; Shen, R. Experimental and numerical investigations of the effect of charge density and scale on the heat transfer behavior of $\mathrm{Al} / \mathrm{CuO}$ nano-thermite. Vacuum 2021, 184, 109878. [CrossRef]

4. Pyka, D.; Kurzawa, A.; Bocian, M.; Bajkowski, M.; Magier, M.; Sliwinski, J.; Jamroziak, K. Numerical and Experimental Studies of the ŁK Type Shaped Charge. Appl. Sci. 2020, 10, 6742. [CrossRef]

5. Żochowski, P.; Warchoł, R.; Miszczak, M.; Nita, M.; Pankowski, Z.; Bajkowski, M. Experimental and Numerical Study on the PG-7VM Warhead Performance against High-Hardness Armor Steel. Materials 2021, 14, 3020. [CrossRef] [PubMed]

6. Huang, N.; Tang, H.; Huang, Y. Preparation and electrical performance of exploding foil in slapper detonator. Chin. J. Energetic Mater. 2014, 22, 514-520.

7. Rae, P.; Dickson, P. A review of the mechanism by which exploding bridge-wire detonators function. Proc. Math. Phys. Eng. Sci. 2019, 475. [CrossRef]

8. Manner, V.W.; Yeager, J.D.; Smilowitz, L.; Remelius, D.; Henson, B.F. Function of a PETN-Based Exploding Bridgewire Detonator Post Melt. Propellants Explos. Pyrotech. 2020, 45, 1533-1540. [CrossRef]

9. Rae, P.J. The modeling of weak shock waves in highly porous powder beds and comments on its relevance to exploding bridgewire (EBW) detonators. Shock. Waves 2021, 31, 153-164. [CrossRef]

10. Chen, J.; Li, J.; Wang, Y.; Ren, W.; Li, H. Research on MEMS multi-point exploding metal foil synchronous array. Modern Phys. Lett. B 2021, 2140018. [CrossRef]

11. Zhang, Q.; Zhu, P.; Wang, K.; Xu, C.; Yang, Z.; Shen, R.; Zheng, G. An Exploding Foil Overpressure Actuator for Multipoint Synchronous Initiation and Mach Reflection Generation. Sens. Actuators A Phys. 2020, 314, 112248. [CrossRef]

12. Smilowitz, L.; Henson, B.F.; Remelius, D.; Bowlan, P.; Suvorova, N.; Allison, J.; Cardon, D.; Freeman, M.; Mariam, F.; Meijer, W. Experimental observations of exploding bridgewire detonator function. J. Appl. Phys. 2020, 128, 215901. [CrossRef]

13. Chen, Q.; Li, Y.; Ma, T. Characterization of the super-short shock pulse generated by an exploding foil initiator. Sens. Actuators A Phys. 2019, 286, 91-97. [CrossRef]

14. Yang, Z.; Zheng, G.; Zhu, P.; Xu, C.; Zhang, Q.; Wang, K.; Shen, R. Design, fabrication and characterization of an electricalexplosively actuated MEMS yer-accelerator inserted with parallel bridge foils. Eur. Phys. J. Appl. Phys. 2020, $91,10301$. [CrossRef]

15. Zhu, P.; Chen, K.; Xu, C.; Zhao, S.; Shen, R.; Ye, Y. Development of a monolithic micro chip exploding foil initiator based on low temperature co-fired ceramic. Sens. Actuators A Phys. 2018, 276, 278-283. [CrossRef]

16. Lei, F.; Ye, Q.; Yang, S.; Fu, Q. Study on Electrical Explosion Properties of Cu/Ni Multilayer Exploding Foil Prepared by Magnetron Sputtering and Electroplating. Micromachines 2020, 11, 528. [CrossRef] [PubMed]

17. Song, J.; Guo, T.; Yao, M.; Chen, J.; Ding, W.; Bei, F.; Mao, Y.; Yu, Z.; Huang, J.; Zhang, X.; et al. A comparative study of thermal kinetics and combustion performance of $\mathrm{Al} / \mathrm{CuO}, \mathrm{Al} / \mathrm{Fe}_{2} \mathrm{O}_{3}$ and $\mathrm{Al} / \mathrm{MnO}_{2}$ nanothermites. Vacuum 2020, 176, 109339. [CrossRef]

18. Zhu, M.; Song, B.; Qi, M.; Hu, Z.; Nomoto, K.; Yan, X.; Cao, Y.; Johnson, W.; Kohn, E.; Jena, D.; et al. 1.9-kV AlGaN/GaN Lateral Schottky Barrier Diodes on Silicon. IEEE Electron Device Lett. 2015, 36, 375-377. [CrossRef]

19. Xu, R.; Chen, P.; Liu, M.; Zhou, J.; Li, Y.; Liu, B.; Chen, D.; Xie, Z.; Zhang, R.; Zheng, Y. 2.7-kV AlGaN/GaN Schottky barrier diode on silicon substrate with recessed-anode structure. Solid State Electron. 2021, 175, 107953. [CrossRef] 
20. Bo, H.; Peng, Z.; Ruiqi, S.; Yinghua, Y.; Lizhi, W.; Yan, H. Design and characterization of micro plane explosion switch with $\mathrm{Al} / \mathrm{CuO}$ reactive multilayer films. High Power Laser Part. Beams 2015, 27, 2563-2571.

21. Hu, B.; Jiao, J.; Zhu, P.; Wu, L.; Ye, Y.; Shen, R. Characterization of electrical explosion of Schottky diode for one-shot switch applications. Eur. Phys. J. Appl. Phys. 2014, 68, 30801. [CrossRef]

22. Grapperhaus, M.J.; Krivokapić, Z.; Kushner, M.J. Design issues in ionized metal physical vapor deposition of copper. J. Appl. Phys. 1998, 83, 35-43. [CrossRef]

23. Dulkin, A.; Ko, E.; Wu, L.; Karim, I.; Leeser, K.; Park, K.J.; Meng, L.; Ruzic, D.N. Improving the quality of barrier/seed interface by optimizing physical vapor deposition of Cu Film in hollow cathode magnetron. J. Vac. Sci. Technol. A 2011, 29, 041514. [CrossRef]

24. Deng, P.; Jiao, Q.; Ren, H. Laminated ammonium perchlorate-based composite by ice-template freezing-induced assembly. J. Mater. Sci. 2021, 56, 2077-2087. [CrossRef]

25. Wang, K.; Xu, C.; Zhu, P.; Zhang, Q.; Yang, Z.; Shen, R. Strategy for increasing flyer launching capacity of electro-explosively actuator by coupling electric explosion and plasma discharge. Sens. Actuators A Phys. 2021, 322, 112609. [CrossRef]

26. Deng, P.; Wang, H.; Yang, X.; Ren, H.; Jiao, Q. Thermal decomposition and combustion performance of high-energy ammonium perchlorate-based molecular perovskite. J. Alloy. Compd. 2020, 827, 154257. [CrossRef] 